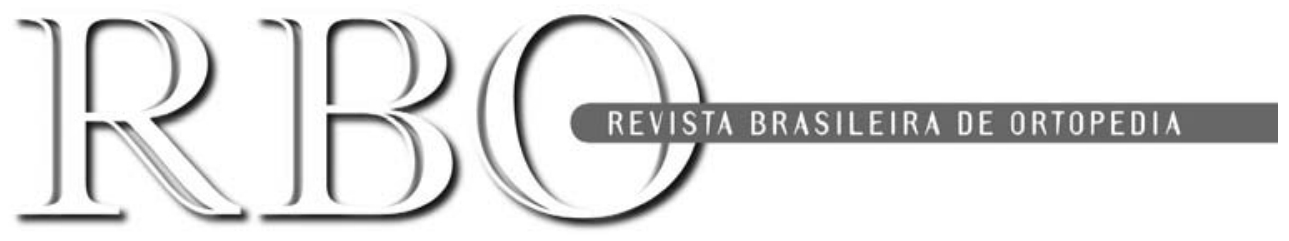

\title{
Editorial
}

\section{Ano novo, novos conselhos, novas notícias}

Iniciamos mais um ano com esta edição da RBO, que já contém um número maior de trabalhos. Esta foi à opção do conselho editorial e da nova diretoria da SBOT, frente ao número cada vez maior de trabalhos enviados para publicação - ao invés de mais números, uma revista com maior numero de trabalhos.

O Conselho Editorial foi renovado, com a entrada dos professores Akira Ishida, Helton Defino e Sergio Checchia, que substituíram os professores J oão Batista Volpon, Flávio Faloppa e Tarcisio Barros, três professores titulares que contribuíram de forma decisiva para indexação da RBO na SciELO. Essa renovação ocorre por força do estatuto da RBO, que determina que cada presidente da SBOT, em conjunto com o Conselho Editorial, renove um terço deste no seu mandato.

O novo conselho renovou também o Corpo Editorial e o Corpo de Consultores, trazendo novos nomes que têm contribuído muito com a RBO em substituição a membros que solicitaram o seu desligamento ou que foram considerados como merecedores de um período de descanso das complicadas funções de revisão editorial. Atendendo a resolução da reunião do Conselho Editorial da RBO no 41을 CBOT no Rio de Janeiro, apresentamos os primeiros Editores Associados: Philippe Hernigou - Paris, França; Fernando Fonseca - Coimbra, Portugal; José Neves - Porto, Portugal; Jacinto Monteiro - Lisboa, Portugal.

A RBO agradece àqueles que se afastaram por qualquer motivo e saúda os novos membros.

Neste editorial transcrevemos o documento que sintetiza a ação da AMB junto à CAPES para valorização da editoração científica brasileira.

Gilberto Luis Camanho Editor-Chefe

\section{Classificação dos periódicos no Sistema QUALIS da CAPES - a mudança dos critérios é URGENTE!}

A Associação Médica Brasileira (AMB), preocupada com o futuro das publicações científicas brasileiras, depois da divulgação dos novos critérios QUALIS da CAPES, organizou uma série de encontros em sua sede em São Paulo. Os Editores das principais revistas médicas do país, diretores da ABEC (Associação Brasileira de Editores Científicos) e os coordenadores das áreas de Medicina II e Medicina III da CAPES trocaram informações e, acima de tudo, elaboraram propostas para aprimorar o processo de avaliação dos periódicos científicos brasileiros pelo novo sistema QUALIS da CAPES. A produção científica classificada pelo QUALIS constituirá um dos itens principais da avaliação dos programas de pós-graduação no último triênio. Considerando que a principal fonte de artigos científicos para as revistas brasileiras é provenientes dos programas de pós-graduação vinculados à CAPES, era muito importante afinar o discurso e garantir uma linguagem comum para todas as partes envolvidas. Do lado dos Editores há receio de que os novos critérios da CAPES possam criar uma subclasse de periódicos baseada exclusivamente no Fator de Impacto ISI. O critério anterior indicava, como ponto de corte, fator de impacto igual a 1. Recentemente, algumas revistas brasileiras conseguiram, com enormes esforços, atingir esse patamar. Entretanto, os novos critérios, além de considerar apenas o fator de impacto, estabeleceram pontos de corte bem mais elevados. Adotando-se essa medida, as revistas brasileiras passariam a ser preteridas pelos orientadores e alunos de pós-graduação - os grandes produtores da ciência brasileira - criando-se assim um círculo vicioso no qual seria difícil a sobrevivência dos nossos periódicos.

Pelo lado da CAPES, falou o professor João Pereira Leite que, além de coordenador da área de Medicina II, é também o atual representante da área de saúde no CTC - Conselho Técnico Científico - órgão máximo da CAPES. Ele, durante uma de nossas reuniões, fez detalhada explanação sobre os critérios adotados nos triênios anteriores e o impacto dos mesmos sobre os programas de pós-graduação do Brasil. Explicou ainda que, frente à evidente melhoria do nível dos programas, era preciso elevar o ponto de corte ou de separação para melhor discriminá-los e estratificálos qualitativamente. A partir dos dados provenientes dos programas - colhidos pelo sistema de coleta CAPES - foi observado que muitos tinham mais de $50 \%$ - alguns mais de $80 \%$ - de sua produção científica publicada em periódicos dos estratos mais elevados. A CAPES, por sua vez, decidiu pela criação de um número maior de estratos para 
poder reclassificar os periódicos. Foi proposta uma escala decrescente segundo o valor do fator de impacto: $A 1, A 2$, B1, B2, B3, B4, B5 e C. Além disso, criou um fator de equivalência segundo o qual, a soma de publicações em revistas de estratos inferiores seria equivalente a um número menor de publicações dos estratos superiores. Assim, por exemplo, para uma determinada área, 2 artigos $B 1$ equivaleriam a 1,2 artigo $A 1 ; 1$ artigo $B 1+1$ artigo $A 2$ equivaleriam a 1,4 artigo A1; 3 artigos B2 equivalem a 1,2 A1. Segundo o professor João Leite, "essa equivalência beneficiaria as revistas com diferentes níveis de qualificação". O professor Leite informou ainda que a nova classificação foi elaborada com base na mediana do fator de impacto das revistas, obtida junto ao Journal Citation Reports (JCR) e calculada anualmente pelo ISI Web of Knowledge. Para o cálculo da mediana foi elaborada uma lista das revistas em que cada área da CAPES publica. De posse dessa lista, bem como dos respectivos fatores de impacto, foi calculada a mediana para cada área e construída a nova estratificação, que varia entre A1, A2, B1 até B5 e C.

Os Editores contra-argumentaram ao professor Leite, lembrando que a característica trienal do processo de avaliação CAPES conferiria um relativo descompasso para a reclassificação dos periódicos, a saber: várias revistas brasileiras terão seu fator de impacto aumentado ou publicado pela primeira vez ao longo de 2010, em especial, as que acabaram de entrar para o ISI. Além disso, teriam que esperar três anos para mudar de categoria dentro do novo QUALIS! Outro questionamento dos Editores diz respeito à escolha do fator de impacto publicado pelo Journal Citation Reports (JCR) como ÚNICO e universal índice para aferição da qualidade dos periódicos. É grande o desvio padrão dos valores dos fatores de impacto das revistas. Certamente por isso, a CAPES utilizou a mediana desses índices para analisar o comportamento da produção dos programas de pós-graduação. De fato, segundo esse critério, algumas especialidades médicas, como as cirúrgicas, têm suas melhores revistas com fator de impacto mais baixo, o que poderia implicar um viés que lhes seria extremamente desfavorável.

Os dois lados concordaram em que a valorização dos periódicos brasileiros é importante para o crescimento e desenvolvimento científico nacional. Para garantir e estimular esse círculo virtuoso é preciso, entre outros, estimular e fomentar a citação de artigos de autores nacionais, intensificar os esforços de Editores, revisores e autores dos periódicos, para aumentar a qualidade dos artigos e, por outro lado, obter maior apoio dos órgãos governamentais, principalmente da CAPES e do CNPq, no que diz respeito, respectivamente, à administração de recursos financeiros e à estratificação qualitativa.

Os resultados dessas discussões foram apresentados em diversos encontros de Editores, coordenadores de programas de pós-graduação e pesquisadores, sendo complementados por novas sugestões. Que estas idéias, abaixo descritas, sirvam de conclusão para este editorial e que representem, ao mesmo tempo, uma ferramenta importante para a mudança dos critérios de classificação dos periódicos no sistema QUALIS da CAPES por parte dos organismos responsáveis. As propostas são as seguintes:

- A análise qualitativa dos periódicos brasileiros deve ser reavaliada e não envolver somente o Fator de Impacto publicado pelo J ournal Citation Reports (JCR);

- Devem ser consideradas e respeitadas as particularidades de cada área de interesse ou de cada especialidade;

- O parque editorial brasileiro, diferente do restante do mundo que é mantido basicamente pela iniciativa privada, é mantido à custa de Universidades públicas e privadas e associações científicas de classe;

- Os periódicos brasileiros necessitam de maior apoio e incentivo, que poderão vir na forma de: bolsa para editores, apoio financeiro à publicação, maior visibilidade para os periódicos nacionais no Exterior, critérios mais objetivos e abrangentes para classificação qualitativa, e apoio diferenciado e correspondente ao desempenho de cada revista;

- Apoio à internacionalização dos periódicos científicos por meio de suporte para profissionalização do processo editorial e divulgação das revistas em outros países;

- Atualização contínua da classificação dos periódicos junto ao novo QUALIS sem precisar esperar pelo prazo da avaliação trienal;

- Participação de representantes de classe (ABEC, AMB, entre outros) no processo decisório junto ao sistema QUALIS da CAPES;

- Estímulo vigoroso à citação diretamente na fonte que são os programas de pós-graduação (por exemplo, determinando que programas de $P G$ notas 6 e 7, além de deverem obrigatoriamente ter uma porcentagem de publicações em revista de alto impacto, devam ter também cotas percentuais de publicações em periódicos nacionais. Com isso estarão contemplados os dois extremos da produção científica, pois os jovens e futuros pesquisadores iniciam sua carreira publicando em periódicos nacionais sob orientação de pesquisadores experientes.

Por fim, para corroborar todas essas ações e preocupada com o desenrolar das repercussões do novo QUALIS da CAPES e outras avaliações de periódicos, a ABEC (Associação Brasileira dos Editores Científicos) dedicou em seu último Encontro Nacional de Editores Científicos, realizado em novembro de 2009, três dias ao Fórum de áreas. Neste, representantes da CAPES e Editores de todas as áreas do conhecimento científico discutiram longamente 0 assunto e ao final propuseram as Diretrizes do Fórum de Áreas do XI I Encontro Nacional dos Editores Científicos - 2009, que será oportunamente enviado a todas as agências brasileiras de fomento, e que deverá ocorrer periodicamente, pois o processo é contínuo. 